\title{
Diagnostic and prognostic value of serum periostin in patients with non-small cell lung cancer
}

\author{
Chun-Hua $X^{1,2}$, Wei Wang ${ }^{1,2}$, Yong Lin ${ }^{3}$, Li-Hua Qian ${ }^{4}$, Xiu-Wei Zhang ${ }^{5}$, Qing-Bo \\ Wang $^{6}$, Li-Ke Yu ${ }^{1}$ \\ ${ }^{1}$ Endoscopic Center of Nanjing Chest Hospital, Nanjing, Jiangsu 210029, China \\ ${ }^{2}$ Clinical Center of Nanjing Respiratory Diseases and Imaging, Nanjing, Jiangsu 210029, China \\ ${ }^{3}$ Department of Respiratory Medicine, Nanjing Chest Hospital, Nanjing, Jiangsu 210029, China \\ ${ }^{4}$ Department of Respiratory Medicine, Nanjing Pukou Central Hospital, Nanjing, Jiangsu 211800, China \\ ${ }^{5}$ Department of Respiratory Medicine, Affiliated Jiangning Hospital of Nanjing Medical University, Nanjing, Jiangsu 211100, \\ China \\ ${ }^{6}$ Department of Geriatrics Medicine, Nanjing Second Hospital, Nanjing, Jiangsu 210003, China
}

Correspondence to: Like Yu, email: Ikyu54@126.com

Keywords: periostin, non-small cell lung cancer, prognosis, diagnosis, biomarker

Received: June 20, $2016 \quad$ Accepted: October 26, $2016 \quad$ Published: November 01, 2016

\section{ABSTRACT}

The periostin protein is expressed in a variety of human malignancies. The aim of this study was to explore the diagnostic and prognostic value of serum periostin levels in patients with non-small cell lung cancer (NSCLC). We measured serum periostin levels by ELISA in 296 NSCLC patients, 120 benign lung diseases (BLD) patients and 160 healthy controls. The levels of serum periostin in NSCLC patients were significantly elevated compared with those in healthy controls $(P<0.001)$ and BLD patients $(P<0.001)$. Using a cutoff value of $30.87 \mathrm{ng} / \mathrm{ml}$, the sensitivity and specificity of periostin in differentiating between NSCLC patients and BLD patients, and between NSCLC patients and healthy controls was, 48.6 and $91.7 \%$, and 51.4 and $\mathbf{9 7 . 5 \%}$, respectively. Kaplan-Meier log rank analysis revealed that the higher serum periostin levels group had a poorer progression-free survival (PFS) and overall survival (OS) compared with lower periostin group $(P=0.024, P=0.015$, respectively). Further univariate and multivariate Cox regression analysis showed that serum periostin was an independent risk factor of prognosis of NSCLC patients. In conclusion, our study suggests that serum periostin could be considered as a diagnostic and prognostic marker for NSCLC patients.

\section{INTRODUCTION}

Lung cancer is the leading cause of cancer-related death in the world [1]. Non-small cell lung cancer (NSCLC) accounts for up to $80-85 \%$ of lung cancer [2]. When first diagnosed, most of the lung cancer patients have advanced stage, so that patients have little effective treatment, and this presents five years survival rates of less than $15 \%$ $[3,4]$. Several tumor markers such as carcinoembryonic antigen (CEA), cytokeratin 19 fragment (CYFRA21-1), and neuron-specific enolase (NSE) have been used as biomarker for lung cancer. Nevertheless, none of them showed satisfactory for diagnosis because of their low sensitivity and specificity. Hence, biomarkers for diagnosis and prognosis of lung cancer are urgently needed [5].

Periostin, a secreted matrix N-glycoprotein, which is a component of NH2-terminal signal peptide sequence, internal homologous repeats, cysteine-rich domain, and hydrophilic $\mathrm{COOH}$-terminal domain [6,7]. Previous studies showed that periostin was overexpressed in various human tumors [8-11]. Many studies have indicated that periostin overexpression or raised serum periostin level is associated with poor patient outcomes [12, 13]. Periostin is overexpressed in lung cancer tissues and associated with the prognosis [14-16], but the correlation between serum periostin and NSCLC progression, as well as the 
Table 1: The characteristics of NSCLC patients, BLD patients and healthy controls

\begin{tabular}{|c|c|c|c|c|}
\hline Variables & NSCLC & BLD & Healthy controls & $P$ value \\
\hline Subject, No & 296 & 120 & 160 & \\
\hline Age (year) & $56.5 \pm 12.7$ & $55.8 \pm 11.8$ & $57.8 \pm 11.7$ & $>0.05$ \\
\hline Gender $(\mathrm{n}, \%)$ & & & & $>0.05$ \\
\hline Male & $180(60.8)$ & $70(58.3)$ & $96(60.0)$ & \\
\hline Female & $116(39.2)$ & $50(41.7)$ & $64(40.0)$ & \\
\hline Smoking condition & & & & $>0.05$ \\
\hline Non-smoker & $160(54.1)$ & $65(54.2)$ & $90(56.3)$ & \\
\hline Smoker & $136(45.9)$ & $55(45.8)$ & $70(43.7)$ & \\
\hline \multicolumn{5}{|l|}{ Histology } \\
\hline $\mathrm{ADC}$ & $164(55.4)$ & & & \\
\hline $\mathrm{SCC}$ & $132(44.6)$ & & & \\
\hline \multicolumn{5}{|l|}{ Lymph node metastasis } \\
\hline Negative & $172(58.1)$ & & & \\
\hline Positive & 124 (41.9) & & & \\
\hline \multicolumn{5}{|l|}{ Distant metastases } \\
\hline Negative & $129(43.6)$ & & & \\
\hline Positive & $167(56.4)$ & & & \\
\hline \multicolumn{5}{|l|}{ Stage } \\
\hline I-II & $110(37.2)$ & & & \\
\hline III-IV & $186(62.8)$ & & & \\
\hline \multicolumn{5}{|l|}{ BLD } \\
\hline Tuberculosis & & $40(33.3)$ & & \\
\hline Bronchiectasis & & $30(25.0)$ & & \\
\hline Lung bullae & & $30(25.0)$ & & \\
\hline Inflammatory pseudotumor & & $20(16.7)$ & & \\
\hline
\end{tabular}

Abbreviations: NSCLC, non-small-cell lung cancer; BLD, benign lung diseases; ADC, Adenocarcinoma; SCC, Squamous cell carcinoma.

effects of periostin on survival of NSCLC, has not been fully assessed.

In the present study, we explored the correlation between serum periostin and clinicopathological variables and patient survival. Our results showed that the evaluation of serum periostin could be a valuable biomarker for NSCLC.

\section{RESULTS}

\section{Clinical characteristics}

The mean age of the NSCLC patients $(56.5 \pm 12.7$ years) was not obviously different from BLD patients $(55.8 \pm 11.8$ years $)$ and healthy controls $(57.8 \pm 11.7$ years). The proportion of male gender is $60.8 \%$ of the NSCLC patients, $58.3 \%$ of the BLD patients and $60.0 \%$ of the healthy controls, respectively, with no significantly difference $(P>0.05)$. At the time of diagnosis, 110 patients were at stage I + II and 186 patients were at stage III + IV, $41.9 \%$ of the patients with lymph node metastases, and $56.4 \%$ with distant metastases. The patients' clinical characteristics are presented in Table 1 .

\section{Serum levels of periostin in NSCLC patients, BLD patients and healthy controls}

As shown in Figure 1, the levels of serum periostin were significantly higher in NSCLC patients compared with those in healthy controls $(49.46 \pm 8.46 \mathrm{ng} / \mathrm{ml}$ vs. $21.27 \pm 3.42 \mathrm{ng} / \mathrm{ml}, P<0.001)$, and those in BLD patients $(49.46 \pm 8.46 \mathrm{ng} / \mathrm{ml}$ vs. $24.11 \pm 4.67 \mathrm{ng} / \mathrm{ml}, P<0.001)$. However, Serum periostin levels were similar in healthy controls and BLD patients $(P>0.05)$. These results show that periostin can be used as a biomarker for the diagnosis of lung cancer. 


\section{ROC analysis of serum periostin levels in NSCLC patients}

To evaluate the value of serum periostin as a marker, ROC curves was applied to calculate the sensitivity and specificity of this marker in separating NSCLC patients from healthy controls and BLD patients. As shown in Figure 2, an area under the curve (AUC) value for serum periostin reached 0.867 and 0.846 , respectively. Using a cutoff value of $30.87 \mathrm{ng} / \mathrm{ml}$, the sensitivity and specificity of serum periostin in differentiating between NSCLC patients and BLD patients, and between NSCLC patients and healthy controls was, 48.6 and $91.7 \%$, and 51.4 and $97.5 \%$, respectively. These results showed that periostin was a worthy diagnostic marker for NSCLC.

The diagnostic value of periostin in combination with CEA was also analyzed. The results indicated that the sensitivity and specificity of these two markers in differentiating between NSCLC patients and BLD patients,

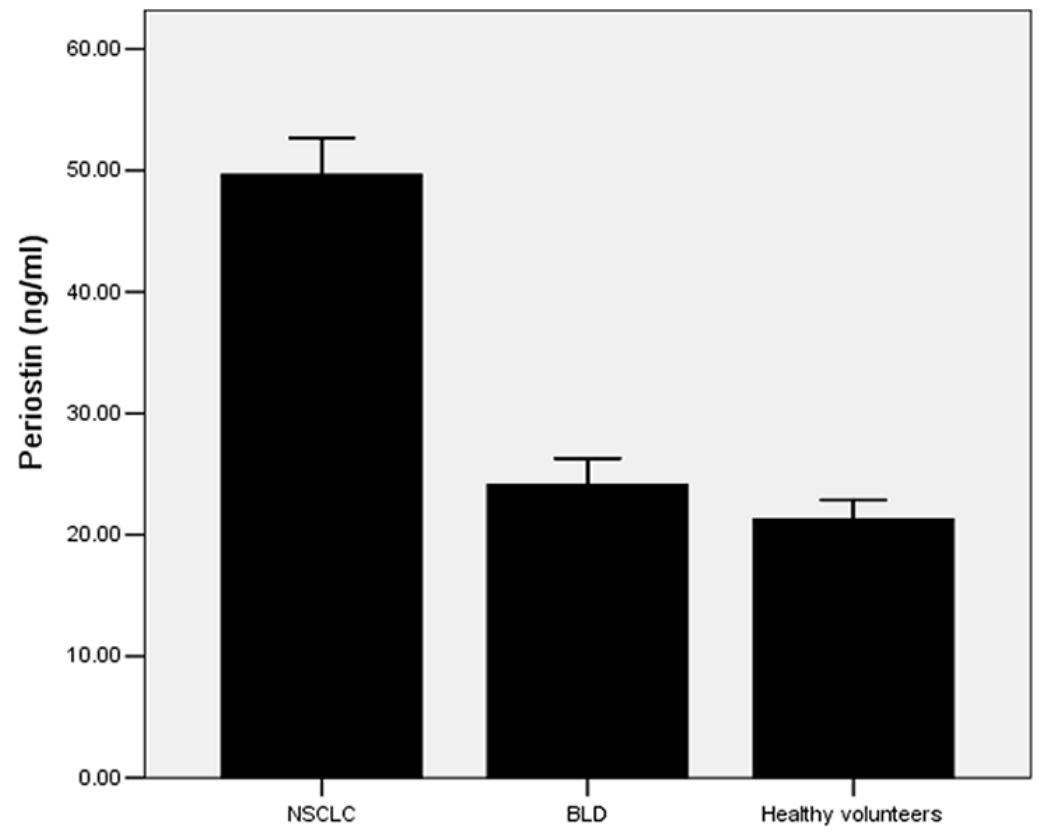

Figure 1: Serum levels of periostin in NSCLC patients, BLD patients and healthy controls. Among 296 NSCLC patients, the serum levels of periostin were $(49.64 \pm 8.46) \mathrm{ng} / \mathrm{ml}$, which were significantly higher than those of BLD patients $(24.11 \pm 4.67) \mathrm{ng} /$ $\mathrm{ml}$ and healthy controls $(21.27 \pm 3.42) \mathrm{ng} / \mathrm{ml}(P<0.001)$
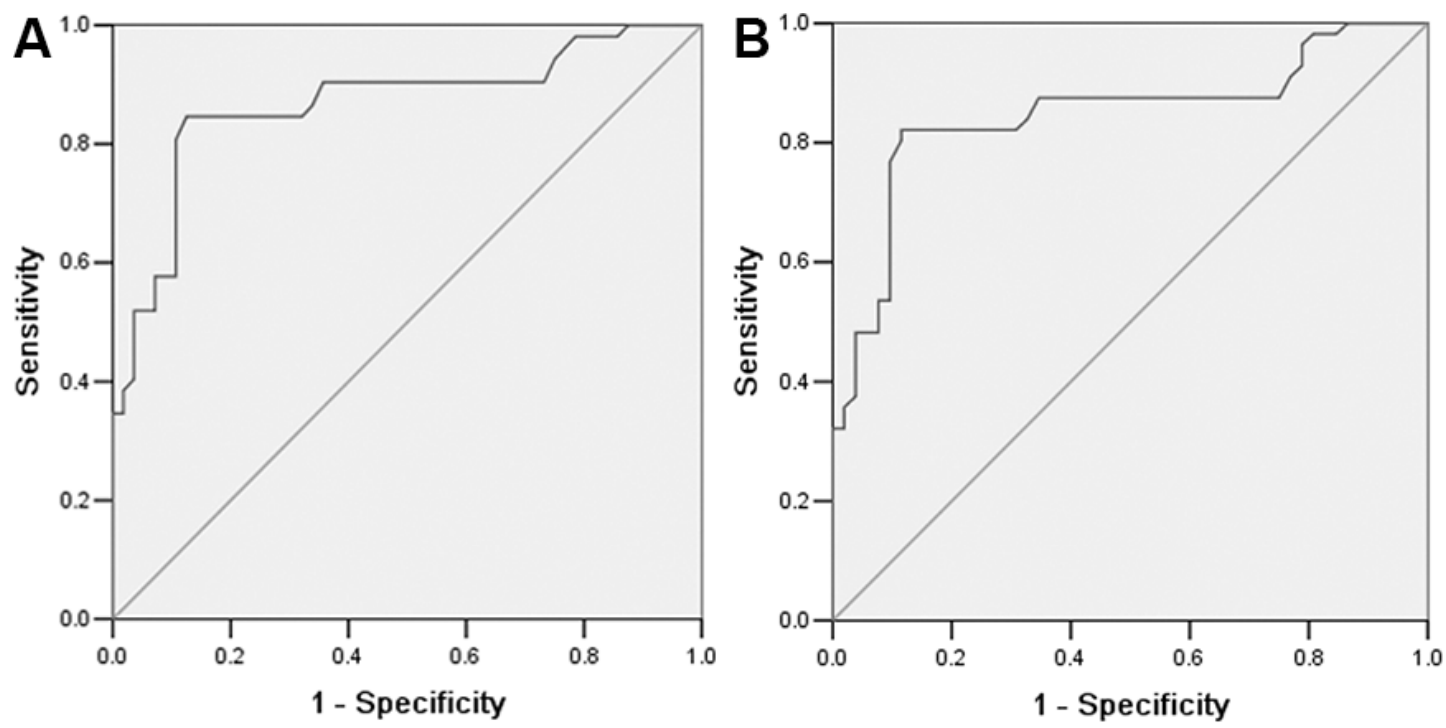

Figure 2: ROC analysis of periostin for differentiation of NSCLC patients from healthy controls (A) and from BLD patients (B). The analysis resulted in an AUC of 0.867 (NSCLC patients vs. healthy controls) and 0.846 (NSCLC patients vs. BLD patients), respectively. 
Table 2: Serum levels of periostin in the three groups and clinical features in the NSCLC group

\begin{tabular}{|c|c|c|c|}
\hline Group & $N$ & Periostin (ng/ml) & $P$ value \\
\hline Healthy controls & 160 & $21.27 \pm 3.42$ & \\
\hline BLD & 120 & $24.11 \pm 4.67$ & $0.001 *$ \\
\hline NSCLC & 296 & $49.64 \pm 8.46$ & \\
\hline \multicolumn{4}{|c|}{ Clinical variables in NSCLC group } \\
\hline Age (year) & & & 0.714 \\
\hline$\leq 60$ & 100 & $49.34 \pm 8.67$ & \\
\hline$>60$ & 196 & $50.71 \pm 8.44$ & \\
\hline Gender & & & 0.412 \\
\hline Male & 180 & $49.18 \pm 8.02$ & \\
\hline Female & 116 & $50.53 \pm 9.59$ & \\
\hline Smoking condition & & & 0.923 \\
\hline Non-smoker & 160 & $49.47 \pm 7.85$ & \\
\hline Smoker & 136 & $49.68 \pm 9.07$ & \\
\hline Histology & & & 0.367 \\
\hline $\mathrm{ADC}$ & 164 & $48.78 \pm 8.48$ & \\
\hline SCC & 132 & $51.88 \pm 8.49$ & \\
\hline Lymph node metastasis & & & $0.012 *$ \\
\hline Negative & 172 & $47.02 \pm 8.61$ & \\
\hline Positive & 124 & $52.83 \pm 8.44$ & \\
\hline Distant metastases & & & $0.001 *$ \\
\hline Negative & 129 & $42.67 \pm 7.17$ & \\
\hline Positive & 167 & $55.39 \pm 10.86$ & \\
\hline Stage & & & $0.008^{*}$ \\
\hline I-II & 110 & $45.81 \pm 7.16$ & \\
\hline III-IV & 186 & $53.48 \pm 8.08$ & \\
\hline
\end{tabular}

Abbreviations: NSCLC, non-small-cell lung cancer; BLD, benign lung diseases; ADC, Adenocarcinoma; SCC, Squamous cell carcinoma.

*Significant difference.

and between NSCLC patients and healthy controls was, 61.8 and $95.0 \%$, and 72.3 and $98.8 \%$, respectively.

\section{Association between periostin levels and clinicopathological variables}

The association between the periostin levels and the clinicopathologic variables in NSCLC patients was analyzed, and the result is summarized in Table 2. The levels of periostin were higher in III-IV stage NSCLC patients compared with those in I-II stage patients $(P=0.008)$. Furthermore, the serum levels of periostin were obviously higher in patients with lymph node metastases than those without $(P=0.012)$. Meanwhile, statistically significant differences in periostin levels were found between NSCLC patients with distant metastases and those patients without distant metastases $(P=0.001)$. However, periostin levels were not associated with age
( $P=0.714)$, gender $(P=0.412)$, histology $(P=0.367)$, and smoking condition $(P=0.923)$. After all, these results indicated that periostin levels in NSCLC patients were associated with the progression and metastasis, which could be considered as a potential biomarker to predict NSCLC patients.

\section{Serum periostin levels indicates a favorable prognosis of NSCLC patients}

To assess the prognostic value of the serum periostin levels, we used serum periostin cutoff value $30.87 \mathrm{ng} / \mathrm{ml}$, which was calculated from ROC analysis, as a threshold to classified NSCLC patients into two groups, high serum periostin group (periostin $\geq 30.87 \mathrm{ng} / \mathrm{ml}$ ) and low serum periostin group (periostin $<30.87 \mathrm{ng} / \mathrm{ml}$ ). As shown by Kaplan-Meier log rank analysis, the higher serum periostin levels group was correlated with a shorter PFS 
and OS, compared with lower serum periostin levels group ( $P=0.024$ and $P=0.015$, respectively) (Figure 3). Further analysis using univariate and multivariate Cox regression showed that serum periostin levels were independent risk factors of prognosis of NSCLC patients (Table 3). Meanwhile, TNM stage and distant metastases were found to be associated with survival.

\section{DISCUSSION}

Periostin is overexpressed in various types of cancer tissues and may affect some aspects of biology, such as tumor angiogenesis, invasion and metastasis $[17,18]$. Previous studies have showed that periostin has been upregulated in NSCLC tissue, however, these studies were restricted to quantitative polymerase chain reaction or immunohistochemical assessment of periostin expression and did not concern its serum levels [14, 15, 19]. In the present study, we found that serum periostin levels were increased in NSCLC patients compared with BLD patients or healthy controls. Using a cutoff value of $30.87 \mathrm{ng} / \mathrm{ml}$, serum periostin showed a valuable biomarker for separating NSCLC patients from BLD patients and the individuals. These data reinforced the diagnostic value of periostin levels in NSCLC. The diagnostic value of periostin in combination with CEA was also analyzed. The results indicated that combined detection of these two markers had a better diagnostic value than periostin or CEA alone. This may offer a new method in differentiating NSCLC patients and the controls.

Periostin has been measured in the serum of NSCLC patients by chemiluminescence assays. Notably, this study showed no difference between NSCLC patients and the controls, and there was also no correlation between the periostin level and sex, stage, lymph node status or distant metastasis [20]. However, our results showed that elevated serum periostin levels were associated with advanced

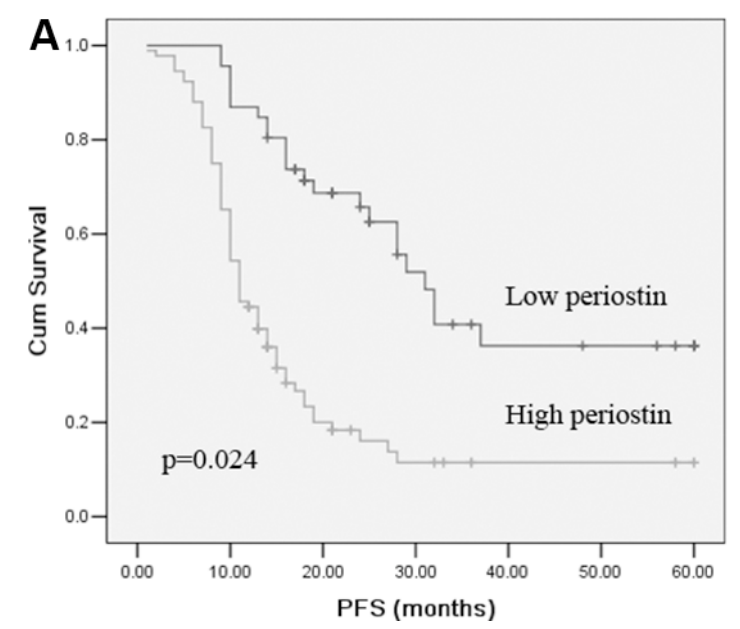

disease stage, lymph node and distant metastases, and there was no significant associations of periostin levels with age, gender, smoking condition and histology. These results indicated that periostin levels were associated with the progression and metastasis NSCLC, which could be serve as a potential biomarker to predict NSCLC patients.

In the present work, we observed that there was a significant correlation between serum periostin levels and NSCLC patients survival. Our results indicated that high periostin was significantly associated with a decreased PFS and OS in univariate analysis. This relationship was further demonstrated in the survival curves. Multivariate analysis also showed that periostin was an independent prognostic factor for NSCLC, which is in line with the data reported for tissue periostin expression using immunohistochemical techniques $[14,19]$. The prognostic utility of tissue periostin expression has also been established in other malignancies $[21,22]$. Concerning the circulating periostin levels, there was strong evidence that serum level of periostin in NSCLC and colorectal cancer patients is significantly elevated [20, 23].

In conclusion, increased serum periostin levels were significantly associated with poor prognosis. Our study provides evidence that periostin can be considered of diagnostic and prognostic utility in NSCLC.

\section{MATERIALS AND METHODS}

\section{Patients}

Three separate groups were included. The first group included 296 patients with NSCLC, who examined at the Nanjing Chest Hospital from January 2011 to May 2014. All patients' histopathological classification was determined according to the WHO criteria, and staged classification was defined according to the 7 th edition of UICC TNM staging system [24]. Follow-up lasted

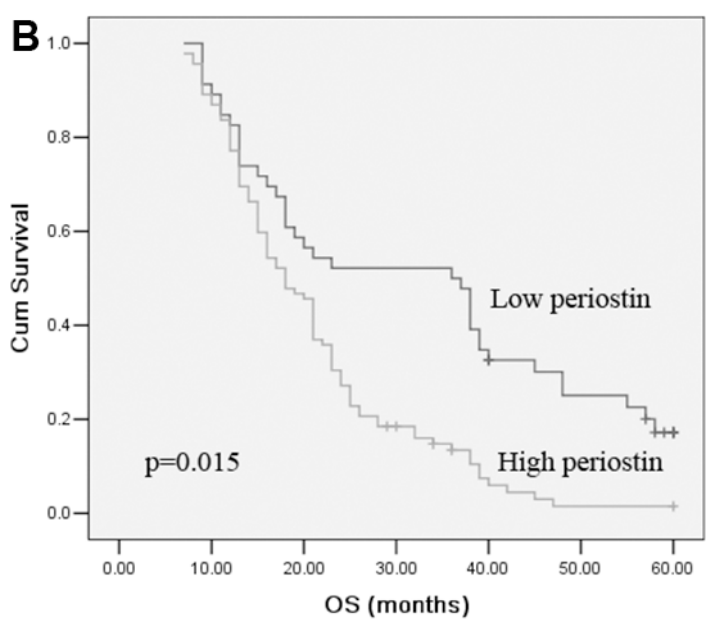

Figure 3: Kaplan-Meier survival curves for PFS (A) and OS (B) in NSCLC patients with high- and low- serum periostin levels group. Log-rank test determined that the PFS and OS in high serum periostin group were significantly shorter than those in the low serum periostin group $(P=0.024 ; P=0.015)$. 
Table 3: Univariate and multivariate Cox proportional hazards model for OS and PFS in NSCLC patients

\begin{tabular}{|c|c|c|c|c|c|c|}
\hline \multirow[t]{2}{*}{ Variables } & \multicolumn{3}{|c|}{ Univariate } & \multicolumn{3}{|c|}{ Multivariate } \\
\hline & HR & $95 \% \mathrm{CI}$ & $P$ value & HR & $95 \% \mathrm{CI}$ & $P$ value \\
\hline \multicolumn{7}{|l|}{ OS } \\
\hline Age $(<60 v s . \geq 60)$ & 0.414 & $0.057-3.020$ & 0.384 & 0.999 & $0.880-1.134$ & 0.983 \\
\hline Gender(female vs. male) & 0.812 & $0.156-4.215$ & 0.804 & 1.125 & $0.238-5.318$ & 0.882 \\
\hline $\begin{array}{l}\text { Smoking status (smoker vs. } \\
\text { nonsmoker) }\end{array}$ & 1.245 & $0.420-3.695$ & 0.692 & 0.809 & $0.533-1.227$ & 0.318 \\
\hline $\begin{array}{l}\text { Histology(Adenocarcinoma } v s . \\
\text { Squamous) }\end{array}$ & 0.546 & $0.249-1.199$ & 0.132 & 0.971 & $0.402-2.346$ & 0.949 \\
\hline $\begin{array}{l}\text { Lymph node metastasis (Positive } \\
\text { vs. Negative) }\end{array}$ & 1.395 & $0.934-2.085$ & 0.104 & 1.609 & $0.695-3.723$ & 0.266 \\
\hline Stage (I-II vs. III-IV) & 0.545 & $0.312-0.952$ & $0.033^{*}$ & 0.395 & $0.172-0.909$ & $0.029 *$ \\
\hline $\begin{array}{l}\text { Distant metastases (Positive vs. } \\
\text { Negative) }\end{array}$ & 1.542 & $0.672-2.194$ & $0.001 *$ & 1.227 & $1.033-1.458$ & $0.002 *$ \\
\hline Periostin (high $v s$. low) & 1.987 & $1.025-3.014$ & $0.039^{*}$ & 1.860 & $1.102-3.918$ & $0.032 *$ \\
\hline \multicolumn{7}{|l|}{ PFS } \\
\hline Age $(<60 v s . \geq 60)$ & 1.109 & $0.724-1.698$ & 0.635 & 0.995 & $0.963-1.029$ & 0.778 \\
\hline Gender(female $v s$. male) & 0.387 & $0.064-2.360$ & 0.303 & 0.974 & $0.229-4.142$ & 0.972 \\
\hline $\begin{array}{l}\text { Smoking status (smoker vs. } \\
\text { nonsmoker) }\end{array}$ & 1.436 & $0.364-5.663$ & 0.605 & 0.538 & $0.132-2.184$ & 0.386 \\
\hline $\begin{array}{l}\text { Histology(Adenocarcinoma vs. } \\
\text { Squamous) }\end{array}$ & 0.664 & $0.289-1.528$ & 0.336 & 1.216 & $0.581-2.544$ & 0.603 \\
\hline $\begin{array}{l}\text { Lymph node metastasis (Positive } \\
\text { vs. Negative) }\end{array}$ & 1.054 & $0.354-3.138$ & 0.925 & 1.108 & $0.684-1.794$ & 0.678 \\
\hline Stage (I-II vs. III-IV) & 2.342 & $1.036-5.296$ & $0.041^{*}$ & 2.067 & $1.003-4.262$ & $0.049^{*}$ \\
\hline $\begin{array}{l}\text { Distant metastases (Positive vs. } \\
\text { Negative) }\end{array}$ & 1.352 & $0.578-1.894$ & $0.001 *$ & 1.324 & $0.678-2.324$ & $0.006^{*}$ \\
\hline Periostin (high $v s$. low) & 2.152 & $1.163-3.605$ & $0.015^{*}$ & 2.018 & $1.123-3.285$ & $0.022 *$ \\
\hline
\end{tabular}

Abbreviations: CI, confidence interval; DFS, disease free survival; HR, Hazard ratio; OS, overall survival.

*Significant difference.

through December 2015, with a median follow-up period of 24 months for living patients (range, 3-60 months). Progression-free survival (PFS) was defined as the time interval between the date of diagnosis and the date of disease relapse. Overall survival (OS) was defined as the time interval between the date of diagnosis and the date of death. The second group enrolled 120 sex- and agematched consecutive cases with BLD patients. Diagnoses were pulmonary tuberculosis (40 cases), bronchiectasis (30 cases), lung bullae (30 cases) and inflammatory pseudotumor (20 cases). The third patient group included 160 sex- and age-matched healthy volunteers. Serum samples from this subject group were offered from Central Laboratory of Nanjing Chest Hospital.

The study protocol was approved by the ethics committee of Nanjing Chest Hospital. All patients provided written informed consent before enrollment.

\section{Measurement of serum periostin and CEA levels}

Serum samples from each individual were obtained at the time of diagnosis, before any therapeutic measures were started. Samples were centrifuged at $1500 \times \mathrm{g}$ for $10 \mathrm{~min}$ at $-4^{\circ} \mathrm{C}$. The supernatant was stored at $-80^{\circ} \mathrm{C}$. The periostin levels were determined by ELISA with the commercial periostin ELISA ReadySET-Go kit (eBioscience, San Diego, CA). The levels of CEA were measured by electrochemiluminescence immunoassays on Roche Elecsys 1010 analyzer (Roche Diagnostics; Mannheim, Germany). The upper normal limit for the CEA is $5 \mathrm{ng} / \mathrm{ml}$. All samples were blinded to the technologists running the assays, and the code was broken to the statisticians after the database was constructed. 


\section{Statistical analysis}

Statistical software (SPSS for Windows, version 18) was used for the analysis. Differences between independent groups were examined by the Mann-Whitney U test. To determine the diagnostic accuracy of periostin, receiver operating characteristic (ROC) curves was retrieved from logistic regression analysis and the area under the curve (AUC) was calculated. Univariate survival analysis was performed using the Kaplan-Meier method and the log-rank test. Multivariate analysis was conducted to determine an independent impact on survival using the Cox proportional hazard method. $P<0.05$ was considered statistically significant.

\section{CONFLICTS OF INTEREST}

The authors declare no any conflicts of interest in this work.

\section{REFERENCES}

1. Siegel R, Ma J, Zou Z, Jemal A. Cancer statistics, 2014. CA Cancer J Clin. 2014; 64:9-29.

2. Smith RA, Cokkinides V, Brawley OW. Cancer screening in the United States, 2009: a review of current American Cancer Society guidelines and issues in cancer screening. CA Cancer J Clin. 2009; 59:27-41.

3. Gumireddy K, Li A, Chang DH, Liu Q, Kossenkov AV, Yan J, Korst RJ, Nam BT, Xu H, Zhang L, Ganepola GA, Showe LC, Huang Q. AKAP4 is a circulating biomarker for non-small cell lung cancer. Oncotarget. 2015; 6:17637-47. doi: 10.18632/oncotarget.3946.

4. Xu CH, Sheng ZH, Hu HD, Hao KK, Wang QB, Yu LK. Elevated expression of Cripto-1 correlates with poor prognosis in non-small cell lung cancer.Tumour Biol. 2014; 35:8673-8.

5. Okamura K, Takayama K, Izumi M, Harada T, Furuyama K, Nakanishi Y. Diagnostic value of CEA and CYFRA 21-1 tumor markers in primary lung cancer. Lung Cancer. 2013; 80:45-9.

6. Huang Y, Liu W, Xiao H, Maitikabili A, Lin Q, Wu T, Huang Z, Liu F, Luo Q, Ouyang G. Matricellular protein periostin contributes to hepatic inflammation and fibrosis. Am J Pathol. 2015; 185:786-97.

7. Li Z, Zhang X, Yang Y, Yang S, Dong Z, Du L, Wang L, Wang C. Periostin expression and its prognostic value for colorectal cancer. Int J Mol Sci. 2015; 16:12108-18.

8. Kotobuki Y, Yang L, Serada S, Tanemura A, Yang F, Nomura S, Kudo A, Izuhara K, Murota H, Fujimoto M, Katayama I, Naka T. Periostin accelerates human malignant melanoma progression by modifying the melanoma microenvironment. Pigment Cell Melanoma Res. 2014; 27:630-9.

9. Riener MO, Fritzsche FR, Soll C, Pestalozzi BC, ProbstHensch N, Clavien PA, Jochum W, Soltermann A, Moch H, Kristiansen G. Expression of the extracellular matrix protein periostin in liver tumours and bile duct carcinomas. Histopathology. 2010; 56:600-6.

10. Tsunoda T, Furusato B, Takashima Y, Ravulapalli S, Dobi A, Srivastava S, McLeod DG, Sesterhenn IA, Ornstein DK, Shirasawa S. The increased expression of periostin during early stages of prostate cancer and advanced stages of cancer stroma. Prostate. 2009; 69:1398-403.

11. Zhang Y, Zhang G, Li J, Tao Q, Tang W. The expression analysis of periostin in human breast cancer. J Surg Res. 2010; 160:102-6.

12. Contié S, Voorzanger-Rousselot N, Litvin J, Clézardin P, Garnero P. Increased expression and serum levels of the stromal cell-secreted protein periostin in breast cancer bone metastases. Int J Cancer. 2011; 128:352-60.

13. Lv Y, Wang W, Jia WD, Sun QK, Li JS, Ma JL, Liu WB, Zhou HC, Ge YS, Yu JH, Xia HH, Xu GL. High-level expression of periostin is closely related to metastatic potential and poor prognosis of hepatocellular carcinoma. Med Oncol. 2013; 30:385.

14. Hong LZ, Wei XW, Chen JF, Shi Y. Overexpression of periostin predicts poor prognosis in non-small cell lung cancer. Oncol Lett. 2013; 6:1595-603.

15. Soltermann A, Tischler V, Arbogast S, Braun J, ProbstHensch N, Weder W, Moch H, Kristiansen G. Prognostic significance of epithelial-mesenchymal and mesenchymalepithelial transition protein expression in non-small cell lung cancer. Clin Cancer Res. 2008; 14:7430-7.

16. Morra L, Rechsteiner M, Casagrande S, von Teichman A, Schraml P, Moch H, Soltermann A. Characterization of periostin isoform pattern in non-small cell lung cancer. Lung Cancer. 2012; 76:183-90.

17. Liu Y, Du L.Role of pancreatic stellate cells and periostin in pancreatic cancer progression. Tumour Biol. 2015; 36:3171-7.

18. Xiao ZM, Wang XY, Wang AM. Periostin induces chemoresistance in colon cancer cells through activation of the PI3K/Akt/survivin pathway. Biotechnol Appl Biochem. $2015 ; 62: 401-6$.

19. Takanami I, Abiko T, Koizumi S. Expression of periostin in patients with non-small cell lung cancer: correlation with angiogenesis and lymph angiogenesis. Int J Biol Markers. $2008 ; 23: 182-6$.

20. Sasaki H, Dai M, Auclair D, Fukai I, Kiriyama M, Yamakawa Y, Fujii Y, Chen LB. Serum level of the periostin, a homologue of an insect cell adhesion molecule, as a prognostic marker in nonsmall cell lung carcinomas. Cancer. 2001; 92:843-8.

21. Utispan K, Thuwajit P, Abiko Y, Charngkaew K, Paupairoj A, Chau-in S, Thuwajit C. Gene expression profiling of cholangiocarcinoma-derived fibroblast reveals alterations related to tumor progression and indicates periostin as a poor prognostic marker. Mol Cancer. 2010; 9:13.

22. Nuzzo PV, Rubagotti A, Zinoli L, Ricci F, Salvi S, Boccardo S, Boccardo F. Prognostic value of stromal and 
epithelial periostin expression in human prostate cancer: correlation with clinical pathological features and the risk of biochemical relapse or death. BMC Cancer. 2012; 12:625.

23. Ben QW, Zhao Z, Ge SF, Zhou J, Yuan F, Yuan YZ. Circulating levels of periostin may help identify patients with more aggressive colorectal cancer. Int J Oncol. 2009; 34:821-8.
24. Goldstraw P, Crowley J, Chansky K, Giroux DJ, Groome PA, Rami-Porta R, Postmus PE, Rusch V, Sobin L, International Association for the Study of Lung Cancer International Staging C, Participating I. The IASLC Lung Cancer Staging Project: proposals for the revision of the TNM stage groupings in the forthcoming (seventh) edition of the TNM Classification of malignant tumours. J Thorac Oncol. 2007; 2:706-14. 